\title{
Clinical Decision-making among Emergency Physicians: Experiential or Rational?
}

\author{
Khalid Talal Aldamiri ${ }^{1}$, Faisal Ahmed Alhusain ${ }^{1, *}$, Amal Almoamary ${ }^{2}$, Khalid Alshehri ${ }^{1}$, Nawfal Al Jerian ${ }^{2}$ \\ ${ }^{1}$ College of Medicine, King Saud bin Abdulaziz University for Health Sciences, Riyadh, Saudi Arabia \\ ${ }^{2}$ Department of Emergency Medicine, Ministry of National Guard - Health Affairs, Riyadh, Saudi Arabia
}

\section{ARTICLE INFO}

\section{Article History}

Received 23 April 2018

Accepted 18 August 2018

Keywords

Clinical decisions

emergency medicine

physicians

\begin{abstract}
It has been postulated that everyone has an affinity for one of two cognitive approaches: experiential (intuitive) or rational (conscious). The aim of this study was to analyze the thinking processes of Saudi emergency physicians at nine hospitals in Riyadh. This was a cross-sectional study, which was undertaken in Riyadh using a psychometric tool called the Rational-Experiential Inventory-40. The survey, sent by e-mail to 202 emergency physicians, had a 53\% response rate. Most respondents were male (86\%). The total surveyed participants included consultants (36\%), associate consultants (19\%), registrars, fellow or staff physicians (7\%), and residents (38\%). The results found a mean (standard deviation) score of 3.73 (0.51) for rational approaches to decision-making and 3.09 (0.45) for experiential approaches among the emergency physicians surveyed. The difference of 0.46 between the two scores was not statistically significant $(p=0.23)$. Female emergency physicians tended toward slower logical thinking (rational). Consultant emergency physicians had a higher score for fast intuitive automatic thinking (experiential) than nonconsultant physicians. This was statistically significant, $t_{105}=2.1, p=0.4$. Our results suggest that although both thinking styles are used in clinical decision-making, consultant emergency physicians prefer rational approaches to decision-making.
\end{abstract}

(c) 2018 Atlantis Press International B.V. This is an open access article under the CC BY-NC license (http://creativecommons.org/licenses/by-nc/4.0/).

\section{INTRODUCTION}

Decision-making is an important yet complex task to be performed in any healthcare field. It relies on several mental processes, including perception, memory, and problem-solving skills [1]. Defects in any of these could lead to the medical errors seen in many areas of medicine, including the emergency department [2]. Understanding how decision-making happens, and what flaws could occur during the process, might help reduce medical errors. Decision-making is a cognitive process, and cognition is complex and hierarchical [3]. It starts with simple skill-based tasks that do not require much cognitive input compared with coordination skills [4]. Next come rulebased decisions that make use of clinical guidelines and diagnostic algorithms. More cognitive effort is needed for this, but a clinician can rely greatly on these rules [4]. At the top of the hierarchy is knowledge-based cognition, which involves clinical and diagnostic reasoning and requires a great deal of attentiveness to reach an appropriate end point in a given situation [4].

Many studies performed on healthcare errors and their characteristics have shown that a vulnerability exists in practice when a clinician is faced with a situation that needs integration between knowledge and a real-life situation [4,5]. Diagnostic errors appear to be one of the most common type of error, and are a property of knowledge-based cognitive behavior $[2,6]$. Sometimes other aspects are factored into the analysis of how the diagnostic error occurred,

*Corresponding author. Email: Faisalaalhusain@gmail.com such as lack of information or false-negative results. However, these all stem from a cognitive error [7]. Other types of error exist in different clinical settings. For instance, when it comes to resuscitation in trauma, errors in clinical reasoning predominate, and have been attributed to failure to consider all available information in the disposition of trauma patients [8]. When it comes to errors, various elements could lead to adverse outcomes. One way to understand how they happen is to understand people's cognitive approaches to different situations.

All cognitive approaches can be categorized as either experiential (intuitive) or rational (conscious) and it has been postulated that everyone has an affinity for one of these [9]. A study on emergency medicine physicians registered with the College of Physicians and Surgeons of Ontario reported that they favored rational thinking overall [9]. Having a similar understanding of the cognitive approaches of Saudi emergency physicians could help prevent medical errors and enhance patients' safety. Therefore, the aim of this study was to analyze the thinking processes of Saudi emergency physicians at nine hospitals and medical cities in Riyadh.

\section{MATERIALS AND METHODS}

\subsection{Study Design and Sampling Technique}

Using a cross-sectional design, this study was undertaken in Riyadh, the capital city of Saudi Arabia, to assess whether emergency 
physicians favor an experiential or rational decision-making process. This was achieved using a previously published psychometric tool called the Rational-Experiential Inventory-40 (REI-40). The survey was sent to all the available Saudi emergency physicians working in the targeted hospitals, through their e-mail and personal social networks. A total 202 physicians were contacted (53\% response rate). The electronic survey (Survey Monkey Inc., San Mateo, CA, USA) was provided as a link that included a first page outlining the study objectives, the researchers' contact information, and clearly stating that anonymity would be guaranteed in the final reports and answers would be confidential. The study was approved by the Institutional Review Board, King Abdullah International Medical Research Centre, Ministry of National Guard - Health Affairs, Riyadh, Saudi Arabia.

\subsection{Study Setting and Participants}

This study targeted Saudi emergency physicians working in nine hospitals in Riyadh [King Abdulaziz Medical City, Riyadh Military Hospital, Security Forces Hospital, Ministry of Health hospitals (King Fahad Medical City, King Saud Medical Complex, and Prince Mohammed Bin Abdulaziz Hospital)], university hospitals (King Khalid University Hospital and King Abdullah bin Abdulaziz University Hospital), and King Faisal Specialist Hospital. We included all Saudi emergency physicians, from junior residents to consultants. Physicians who were retired or whose contact information was missing and could not be reached through social networks were excluded.

\subsection{Survey Instrument}

All the physicians were asked to complete an electronic survey of two parts: demographic data (gender, position, and institution) and the REI-40 questionnaire, which aimed to differentiate between faster intuitive automatic thinking (experiential) and slower logical thinking (rational). This tool has been validated in many different populations including paramedics [10], cardiologists [11], and emergency physicians [9]. The Cronbach' $\alpha$ for the tool ranged from 0.74 to 0.91 , indicating high internal consistency and reliability. Participants were asked to indicate their responses to 40 statements using a 5-item Likert scale, ranging from definitely false (1) to definitely true (5).

\subsection{Data Manipulation and Analyses}

Data manipulation and analyses were done using Microsoft Excel (Microsoft, Redmond, WA, USA) and SPSS Statistics for Windows (version 22.0; IBM Corp., Armonk, NY, USA). The REI-40 was scored based on a coding manual provided by the lead investigator of the instrument, which gave reverse coding for some of the statements. Categorical variables were calculated using frequencies and percentages, whereas continuous variables were calculated as mean [standard deviation (SD)] and presented as histogram shapes. A 95\% confidence interval was calculated for the difference between mean rational and mean experiential scores. Independent Student $t$-test was used to assess the differences between means. All tests were considered statistically significant if the $p$-value was $<0.05$.

\section{RESULTS}

Over the study period from September 2017 to January 2018, 107 emergency physicians responded to the survey. All the physicians were in one of the targeted aforementioned hospitals. Most participants were male ( $86 \%$ or 92 physicians). This was slightly higher than the overall ratio between male and female physicians working in Saudi Arabia. According to the Ministry of Health's Yearly Statistics Book 2016 [12], the ratio between male and female physicians is $37: 13$. Of the participants, $36 \%$ were consultants; $19 \%$ associate consultants; $7 \%$ registrar, fellow, or staff physicians; and 38\% residents. Participants' characteristics are summarized in Table 1.

Emergency physicians' mean (SD) rational score was $3.73(0.51)$ and the mean (SD) experiential score was 3.09 (0.45). The difference of 0.46 between the two scores was not statistically significant using Pearson correlation, which gave $p=0.23$. The distribution of the scores was normal, with some overlaps. Figure 1 illustrates the rational and experiential score patterns.

Female emergency physicians tended toward slower logical thinking, with mean (SD) rational scores of 3.80 (0.5) compared with $3.72(0.58)$ for males. Mean (SD) experiential scores were higher for male physicians [3.10 (0.45)] compared with those for females [3.01 $(0.46)]$. However, these results were not statistically significant: $t_{105}=-0.55, p=0.58$ for the gender mean rational scores and $t_{105}=0.77, p=0.44$ for the gender mean experiential scores. Consultant emergency physicians showed a greater capacity for fast intuitive automatic thinking [mean (SD) experiential score $3.21(0.45)$ ] than nonconsultant physicians [mean (SD) experiential score $3.02(0.45)]$. This was statistically significant, $t_{105}=2.1$, $p=0.04$. Table 2 summarizes the comparison of mean REI- 40 scores for 107 respondents on the basis of demographics.

\section{DISCUSSION}

The study examined the thinking processes among emergency physicians in nine Riyadh hospitals to evaluate whether their clinical decision-making is more experiential or rational. The results showed a slight difference between the emergency physicians' mean (SD) rational score of $3.73(0.51)$ and mean (SD) experiential score of $3.09(0.45)$ that was not statistically significant. This suggests that emergency physicians tend to exploit both experiential and rational decision-making approaches, but perhaps favor the rational style [13].

Table $1 \mid$ Demographic data of the respondents $(n=107)$

\begin{tabular}{llrr}
\hline Variables & Category & $\boldsymbol{n}$ & $\%$ \\
\hline Gender & Male & 92 & 86 \\
& Female & 15 & 14 \\
Physician hospital type & Military hospital & 65 & 63 \\
& Ministry of Health hospital & 16 & 16 \\
& University hospital & 19 & 18 \\
& Other hospital & 3 & 3 \\
Position & Consultant & 39 & 36 \\
& Associate consultant & 20 & 19 \\
& Registrar/fellow/staff physician & 7 & 7 \\
& Junior resident & 27 & 25 \\
& Senior resident & 14 & 13 \\
\hline
\end{tabular}

${ }^{\mathrm{a}} n=4$ missing 

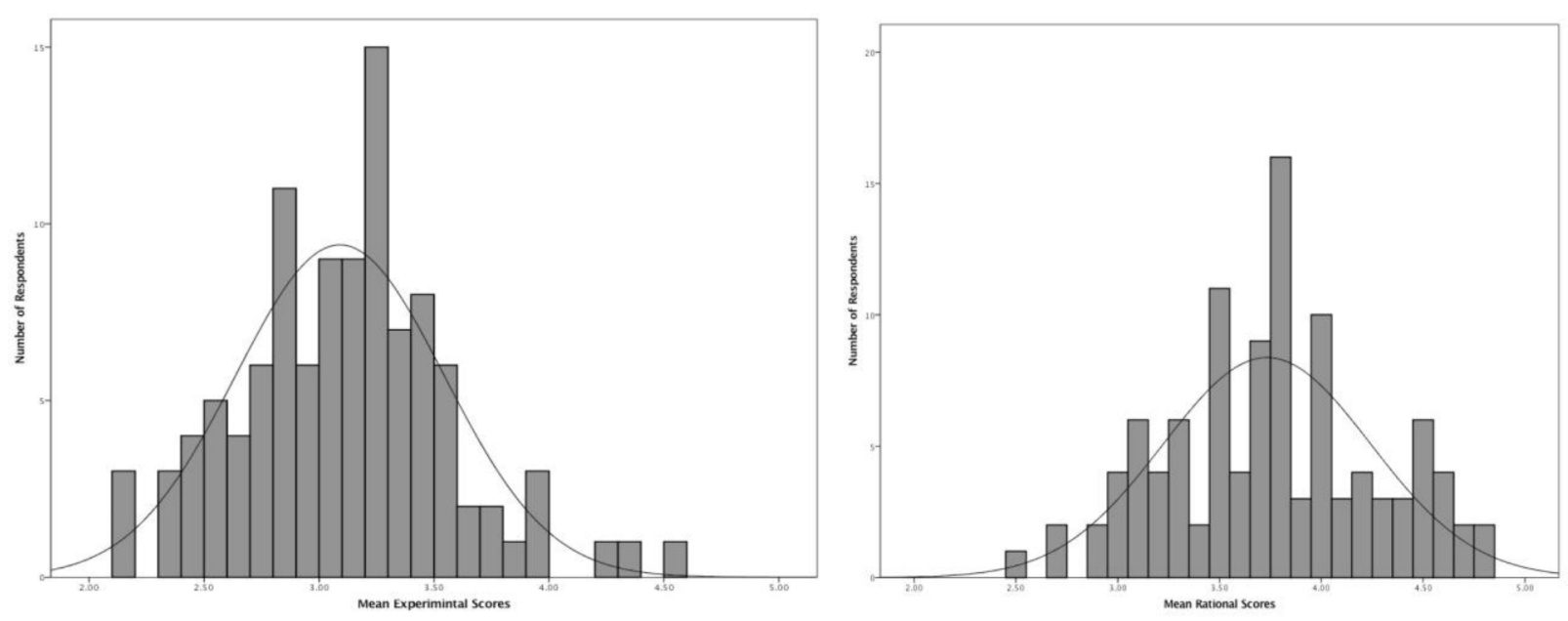

Figure 1 Distribution of Rational-Experiential Inventory-40 (REI-40) scores (experiential and rational) among 107 respondents

Table 2 Comparison of mean Rational-Experiential Inventory (REI-40) scores for 107 respondents on the basis of demographics

\begin{tabular}{lcccccc}
\hline Demographics & $\begin{array}{c}\text { Mean } \\
\text { rational }\end{array}$ & SD & $\boldsymbol{p}$-Value & $\begin{array}{c}\text { Mean } \\
\text { experiential }\end{array}$ & SD & $\boldsymbol{p}$-Value \\
\hline Gender & & & & & & \\
$\quad$ Male & 3.72 & 0.50 & 0.58 & 3.10 & 0.45 & 0.44 \\
$\quad \begin{array}{l}\text { Female } \\
\text { Physician position }\end{array}$ & 3.80 & 0.58 & & 3.01 & 0.46 & \\
$\quad$ Consultant & 3.74 & 0.53 & & & & \\
$\quad$ Nonconsultant & 3.73 & 0.50 & 0.88 & 3.21 & 0.45 & $0.04^{\mathrm{a}}$ \\
\hline
\end{tabular}

${ }^{\mathrm{a}} p<0.05$ is statistically significant; SD, standard deviation.

The greater number of men in the sample might affect the findings. However, it may similarly epitomize a cultural perspective among the emergency physicians that rational decision-making is preferable to experiential decision-making. Moreover, it is possible that these conclusions were a result of social desirability bias. By contrast, Akinci and Sadler-Smith [14] found intuitive (experiential) thinking to be as accurate and effective as analytical thinking. Engebretsen et al. [15] posit that individuals tend to opt for rational decision-making when the risks are great, which several scholars affirm when to it comes to working in the emergency department.

The female emergency physicians were more inclined toward slow logical thinking, which is more analytical and intuitive, with mean (SD) rational score of 3.80 (0.5) compared with 3.72 (0.58) for their male counterparts. Mean (SD) experiential score for males was $3.10(0.45)$ compared with $3.01(0.46)$ for females. Nonetheless, the gender mean rational scores and the gender mean experiential scores were not statistically significant. This finding was consistent with previous studies [15-17]. Numerous surveys have authenticated REI-40 as a psychometric tool with interesting similarity, showing that the female participants favored experiential decision-making more than male respondents did $[9,14,18]$.

A link between years of clinical experience and decision-making was evident in that consultant emergency physicians demonstrated fast intuitive automatic thinking with a mean (SD) experiential score of 3.21 (0.45), whereas nonconsultant physicians had a mean (SD) experiential score of 3.02 (0.45). This finding is in agreement with assertions that decision-making is often based on acquired knowledge as well as the use of approaches that were found to be more effective earlier, notwithstanding discrepancies between the present state and earlier ones [19]. The finding is consistent with the suggestion of McLaughlin et al. [20] that decision-making is a complicated process that differs widely among individuals based on social and context-specific influences. The results give crucial insight into how emergency physicians render decisions. This could be helpful in future research endeavors because it appears that accumulated experience over time plays a significant role in decision-making [21,22].

The evidence generated from this study could be useful when considering change management in the healthcare sector because scholars opine that those favoring rational decision-making tend to be more receptive to evidence-based medicine and knowledge translation efforts [23]. The research results assert the need for decision-support tools that are specifically designed to take into consideration both experiential and rational decision-making approaches. It is conceivable from the findings that male emergency physicians will react in a different manner from female physicians to particular decision-support tools. Physicians with dissimilar practice settings and diverse training backgrounds could also respond differently. Thus, it is critical to undertake careful refinement and specificity before choosing any tool [24]. The findings of the investigation point out the significance of REI-40 as a tool for self-assessment that is relevant to a clinical patient encounter when physicians are cognizant of their decision-making approaches and the inherent inadequacies. When someone is cognizant of their general decision-making approach, they may be in a better position to engage in metacognition, which is described as the practice of "thinking concerning how to think," so as to tackle any noticeable cognitive biases $[25,26]$.

\subsection{Limitations}

One of the limitations of the study was the low response rate of $53 \%$, which makes it difficult to generalize the results to other settings. The voluntary manner in which participants were recruited carries a risk of self-selection bias because the physicians were reached through their e-mail and personal social networks. 
Furthermore, the sample of respondents was skewed toward male participants, and not representative of Saudi emergency physicians because, according to Ministry of Health of Saudi Arabia in the Yearly Statistics Book 2016, the ratio for male and female physicians is $37: 13$.

\section{CONCLUSION}

This study evaluated the general decision-making approach of emergency physicians, showing that although both rational and experiential techniques are used in clinical decision-making, consultant physicians prefer rational decision-making. The results of this investigation have fundamental implications for evidence-based medicine as well as knowledge translation efforts. This study supports the implementation of strategies that are focused on reducing errors in decision-making. Both styles of clinical decision-making are very important and no approach is considered more valuable than another. Future researchers may need to consider evaluating the decision-making approaches of emergency physicians on a broader scale with a larger sample size that is more representative. This could generate data enabling the design of decision-support tools relevant to diverse groups of emergency physicians.

\section{CONFLICTS OF INTEREST}

The authors have no conflicts of interest to declare.

\section{REFERENCES}

[1] Gerrig RJ, Zimbardo PG. Glossary of psychological terms, psychology and life. Boston: Allyn and Bacon; 2002.

[2] Famularo G, Salvini P, Terranova A, Gerace C. Clinical errors in emergency medicine: experience at the emergency department of an Italian teaching hospital. Acad Emerg Med 2000;7;1278-81.

[3] Rasmussen J, Jensen A. Mental procedures in real-life tasks: a case study of electronic trouble shooting. Ergonomics 1974;17;293-307.

[4] Croskerry P. Cognitive forcing strategies in clinical decision making. Ann Emerg Med 2003;41;110-20.

[5] Brennan TA, Leape LL, Laird NM, Hebert L, Localio AR, Lawthers AG, et al. Incidence of adverse events and negligence in hospitalized patients. Results of the Harvard Medical Practice Study I. N Engl J Med 1991;324;370-76.

[6] Glick TH, Workman TP, Gaufberg SV. Suspected conversion disorder: foreseeable risks and avoidable errors. Acad Emerg Med 2000;7;1272-77.

[7] Kuhn GJ. Diagnostic errors. Acad Emerg Med 2002;9;740-50.

[8] Clarke JR, Spejewski B, Gertner AS, Webber BL, Hayward CZ, Santora TA, et al. An objective analysis of process errors in trauma resuscitations. Acad Emerg Med 2000;7;1303-10.

[9] Calder LA, Forster AJ, Stiell IG, Carr LK, Brehaut JC, Perry JJ, et al. Experiential and rational decision making: a survey to determine how emergency physicians make clinical decisions. Emerg Med J 2012;29;811-16.
[10] Jensen JL, Bienkowski A, Travers AH, Calder LA, Walker M, Tavares W, et al. A survey to determine decision-making styles of working paramedics and student paramedics. CJEM 2016;18;213-22.

[11] Sladek RM, Bond MJ, Huynh LT, Chew DPB, Phillips PA. Thinking styles and doctors' knowledge and behaviours relating to acute coronary syndromes guidelines. Implement Sci 2008; $3 ; 23$.

[12] Ministry of Health, Kingdom of Saudi Arabia. (2016). Statistical Yearbook. Retrieved from https://www.moh.gov.sa/en/Ministry/ Statistics/book/Pages/default.aspx

[13] Croskerry P. Individual variability in clinical decision making and diagnosis. In: Croskerry P, Cosby KC, Graber ML, Singh H, editors, Diagnosis: Interpreting the shadows. Oxford, UK: CRC Press, Taylor Francis Group; 2017.

[14] Akinci C, Sadler-Smith E. Assessing individual differences in experiential (intuitive) and rational (analytical) cognitive styles. Int J Sel Assess 2013;21;211-21.

[15] Engebretsen E, Heggen K, Wieringa S, Greenhalgh T. Uncertainty and objectivity in clinical decision making: a clinical case in emergency medicine. Med Health Care Philos 2016;19;595-603.

[16] Djulbegovic B, Beckstead JW, Elqayam S, Reljic T, Hozo I, Kumar A, et al. Evaluation of physicians' cognitive styles. Med Decis Mak 2014;34;627-37.

[17] Sladek RM, Bond MJ, Phillips PA. Age and gender differences in preferences for rational and experiential thinking. Pers Individ Dif 2010;49;907-11.

[18] Phillips WJ, Fletcher JM, Marks AD, Hine DW. Thinking styles and decision making: a meta-analysis. Psychol Bull 2016;142;260-90.

[19] Iannello P, Perucca V, Riva S, Antonietti A, Pravettoni G. What do physicians believe about the way decisions are made? A pilot study on metacognitive knowledge in the medical context. Eur J Psychol 2015;11;691-706.

[20] McLaughlin JE, Cox WC, Williams CR, Shepherd G. Rational and experiential decision-making preferences of third-year student pharmacists. Am J Pharm Educ 2014;78;120.

[21] Riva S, Monti M, Iannello P, Pravettoni G, Schulz PJ, Antonietti A. A preliminary mixed-method investigation of trust and hidden signals in medical consultations. PLoS One 2014;9;e90941.

[22] Cipresso P, Villani D, Repetto C, Bosone L, Balgera A, Mauri M, et al. Computational psychometrics in communication and implications in decision making. Comput Math Methods Med 2015;2015;985032.

[23] Nilsen P, Neher M, Ellström PE, Gardner B. Implementation of evidence-based practice from a learning perspective. Worldviews Evid Based Nurs 2017;14;192-99.

[24] Vannucci A, Kras JF. Decision making, situation awareness, and communication skills in the operating room. Int Anesthesiol Clin 2013;51;105-27.

[25] Norman GR, Monteiro SD, Sherbino J, Ilgen JS, Schmidt HG, Mamede S. The causes of errors in clinical reasoning: cognitive biases, knowledge deficits, and dual process thinking. Acad Med 2017;92;23-30.

[26] Lambe KA, O’Reilly G, Kelly BD, Curristan S. Dual-process cognitive interventions to enhance diagnostic reasoning: a systematic review. BMJ Qual Saf 2016;25;808-20. 